\title{
Uydu Konum Belirleme Sistemlerindeki (GNSS) Güncel Durum ve Son Gelişmeler
}

\author{
Başar KOCA ${ }^{1 *}$, Ayhan CEYLAN ${ }^{2}$ \\ ${ }^{1}$ T.C. Devlet Demiryolları İşletmesi Genel Müdürlüğü \\ (basarkoca@tcdd.gov.tr) ORCID ID 0000-0002-2290-9966 \\ ${ }^{2}$ Selçuk Üniversitesi, Mühendislik Fakültesi, Harita Mühendisliği Bölümü, Konya \\ (aceylan@selcuk.edu.tr) ORCID ID 0000-0003-4408-4245
}

$\ddot{O} \mathbf{z}$

İnsanoğlu yaşadığı her dönemde yeryüzünde bulunduğu yeri bilmek istemiştir. Bu merakı gidermeye yönelik olarak ilk çağlarda kullanılan ilkel konum belirleme yöntemlerinden, günümüz teknolojik gelişmeleri sayesinde uydular yardımıyla dört boyutlu (4D) konum belirleme noktasına gelinmiş̧tir. Konum belirlemelerine yeni bir anlayış getiren Uydu Konum Belirleme sistemleri (Global Navigation Satellite Systems-GNSS), arama-kurtarma, hedef bulma, uçakların görüşün sınırlı yada hiç olmadığı hava koşullarında iniş ve kalkışı gibi askeri alanlarda, her türlü kara, deniz ve hava araçlarının navigasyonu, Jeodezik ve Jeodinamik ölçmeler, kadastral ölçmeler, deformasyon ölçmeleri, araç takip sistemleri, turizm, tarım, ormancılık, spor, güvenlik, hidrografik çalışmalar ve CBS uygulamaları gibi bir çok sivil alanda etkin olarak kullanılmaktadır.

$\mathrm{Bu}$ çalışmada, halen kullanılmakta olan ve yapım aşamasında olan Küresel ve Bölgesel Uydu Konum Belirleme Sistemlerinin güncel durumu ve geleceği hakkında detaylı bilgiler verilmiştir.

Anahtar Kelimeler: Küresel Konum Belirlemeleri, GPS, Glonass, Beidou

\section{Current Status and Recent Developments in Global Positioning Satellite Systems (GNSS)}

\begin{abstract}
Mankind wanted to know the place on earth every time he lived. From the primitive positioning methods used in the early ages to this curiosity, today's technological developments have led to the point of four-dimensional (4D) positioning with the aid of satellites. Global Navigation Satellite Systems (GNSS), which provides a new insight into location determinations, can be used to navigate all kinds of land, sea and air vehicles in military areas such as search and rescue, targeting, aircraft landing and departure Many civilian areas such as geodetic and geodynamic measurements, cadastral measurements, deformation measurements, vehicle tracking systems, tourism, agriculture, forestry, sports, security, hydrographic studies and GIS applications are used effectively.

In this study, detailed information about the current status and future of Global and Regional Satellite Positioning Systems which are still in use and in construction stage are given.
\end{abstract}

Keywords: GNSS, Glonass, Beidou, positioning

* Sorumlu Yazar 


\section{GíRiş}

Küresel Uydu Konum Belirleme Sistemleri (Global Navigation Satellite System-GNSS) sivil ve askeri birçok alanda yaygın olarak kullanılan navigasyon sistemlerinden biridir. Giderek büyüyen ve gelişen Küresel Konum Belirleme Sistemlerini kullananların sayısı da her geçen gün artmaktadır.

Günümüzde Küresel Konum Belirleme sistemlerinde ana servis sağlayıcı olarak üç sistem faaliyet göstermekte olup, bunlar; ABD (GPS), Rusya (GLONASS) ve Avrupa Birliği (Galileo) dir. Çin (Compass/Beidou), Japonya (QZSS) ve Hindistan (IRNSS/GAGAN/NAVIC) ise uluslararas1 platformlarda söz sahibi olma çabalarına devam etmektedir.

$\mathrm{Bu}$ çalışmada, halen kullanılmakta olan Uydu Konum Belirleme Sistemlerindeki güncel gelişmelerin ve bu gelişmelerin sistemlerin işleyişinde ne gibi değişiklikler yaratacağı, yapımı tamamlanmış olan sistemlerde önümüzdeki yıllarda ne gibi güncellemelerin yapılacağ 1 ve bu gelişmeler çerçevesinde ne tür kullanım alanlarına sahip olacağı ele alınacaktır. Ayrıca, halen yapım aşamasında olan sistemlerin hangi aşamada oldukları, sistemlerin hangi tarihte tam kapasiteye çalışır duruma geleceği ve ne şekilde çalışacağ konusunda bilgiler verilecektir.

\section{Küresel Konum Belirleme Sistemleri (GNSS)}

Dünyanın her yerinde, her türlü hava koşullarında uydulardan alınan sinyaller yardımıyla global bir koordinat sisteminde (ITRF), anlık ve yüksek doğrulukta konum, hız ve zaman belirlemeye yarayan bir navigasyon sistemidir (Y1ldız ve Kahveci, 2010).

Uydu Konum Belirleme Sistemle ri, her türlü kara, deniz ve hava araçlarının navigasyonu, insansız uçaklar, arama-kurtarma, hedef bulma, uçakların görüşün sınırlı yada hiç olmadığı hava koşullarında iniş ve kalkışı gibi askeri alanlarda, Jeodezik ve Jeodinamik ölçmeler, kadastral ölçmeler, GNSS destekli fotogrametrik çalışmalar, deformasyon ölçmeleri, araç takip sistemleri, gerçek zamanlı sabit GNSS (CORS) ağları ve CBS uygulamaları gibi bir çok sivil alanda yaygın olarak kullanılmaktadır. Günümüzde konum, hız ve zaman belirleme amaçlı kullanılan başlıca Uydu Konum Belirleme sistemleri;

- $\mathrm{GPS}(\mathrm{ABD})$

- GLONASS (RUSYA)

- BEIDOU/COMPASS (ÇİN)

- QZSS (JAPONYA)

- IRNSS/GAGAN (HINDISTAN)

- GALLILEO (AVRUPA BİRLIĞİ)

olarak sınıflandırabilir.

\subsection{Global Positioning System (GPS)}

GPS projesi, öncelindeki navigasyon sistemlerinin kısıtlı işlevselliklerini aşabilmek amaciyla 1960'larda gelen bir dizi gizli mühendislik çalışması da dahil olmak üzere ilk denemelerde ortaya çıkan birkaç görüşün de birleşmesi ile 1973 yılında ABD Savunma Bakanlığı (DoD) tarafından geliştirilmiştir ve 1994 yılında tam olarak işler hale gelmiştir. GPS'in uzay, yer kontrol ve kullanicı olmak üzere üç bileşeni vardır.

- Esas olarak 24 uydu ile çalışacak şekilde geliştirilen sistem 1994 yılında tam olarak işler hale gelmiştir.

- Askeri amaçlı geliştirilen sistem 1983 yılında sivil kullanıma açılmıştır.

- GPS uyduları orta dünya yörüngesinde (MEO) yaklaşık 20.200 km'lik (12.550 mil) bir yörünge yüksekliğine sahiptir. Her uydu $11^{\mathrm{h}} .58^{\mathrm{m}} \mathrm{l} l \mathrm{k}$ periyod ile Dünya'nın çevresini günde iki kez dolaşmaktadır (Şekil 1). 


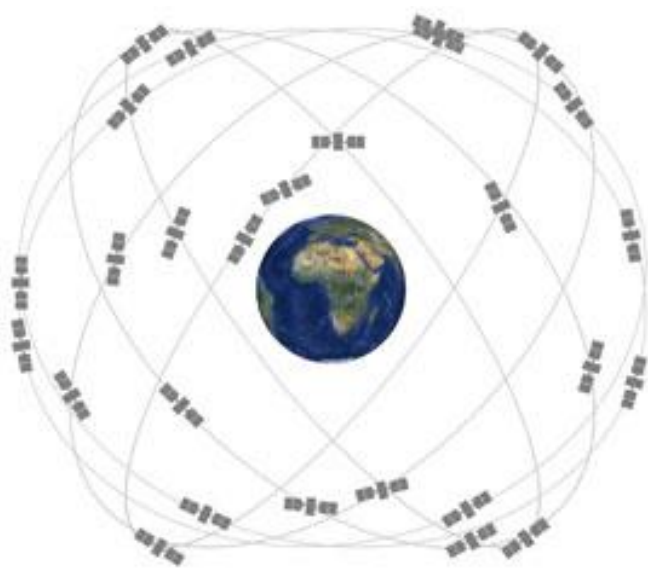

Şekil 1.GPS uydu dağılımı

GPS uyduları, Dünya'yı çevreleyen eşit aralıklarla bulunan altı ayrı yörünge düzlemine yerleştirilmiştir. Uydu yörüngeleri dünyanın neredeyse her noktadan en az dört uydu görebilecek şekilde planlanmıştır.
Haziran 2011'de "Expandable 24" konfigürasyonu kapsamında, GPS, dünyanın birçok yerinde gelişmiş kapsama alanı ile 27 uydu ile daha etkin bir şekilde çalışır hale gelmiştir (URL 1), (URL 2), (GPS World, 2014).

GPS uyduları tarihsel gelişimi sürecinde yeni geliştirilen uydular ile ömürlerini tamamlamış olan eski uyduların yerleri değiştirilerek sürekli olarak iyileştirilmektedir. Bu süreçte, GPS uyduları Block IIA (Advanced), Block

IIR (Replenishment), Block IIR(M) (Modernized), Block IIF ("Follow-on") ve GPS III uyduları olarak isimlendirilmiştir. Mevcut ve yeni nesil GPS uydularının özellikleri Tablo 1'de verilmiştir. 18 Nisan 2017 tarihi itibari ile GPS uydu sisteminde 31 adet operasyonel uydu bulunmaktadır (URL $1)$.

Tablo 1. GPS uyduları ve özellikleri (URL3)

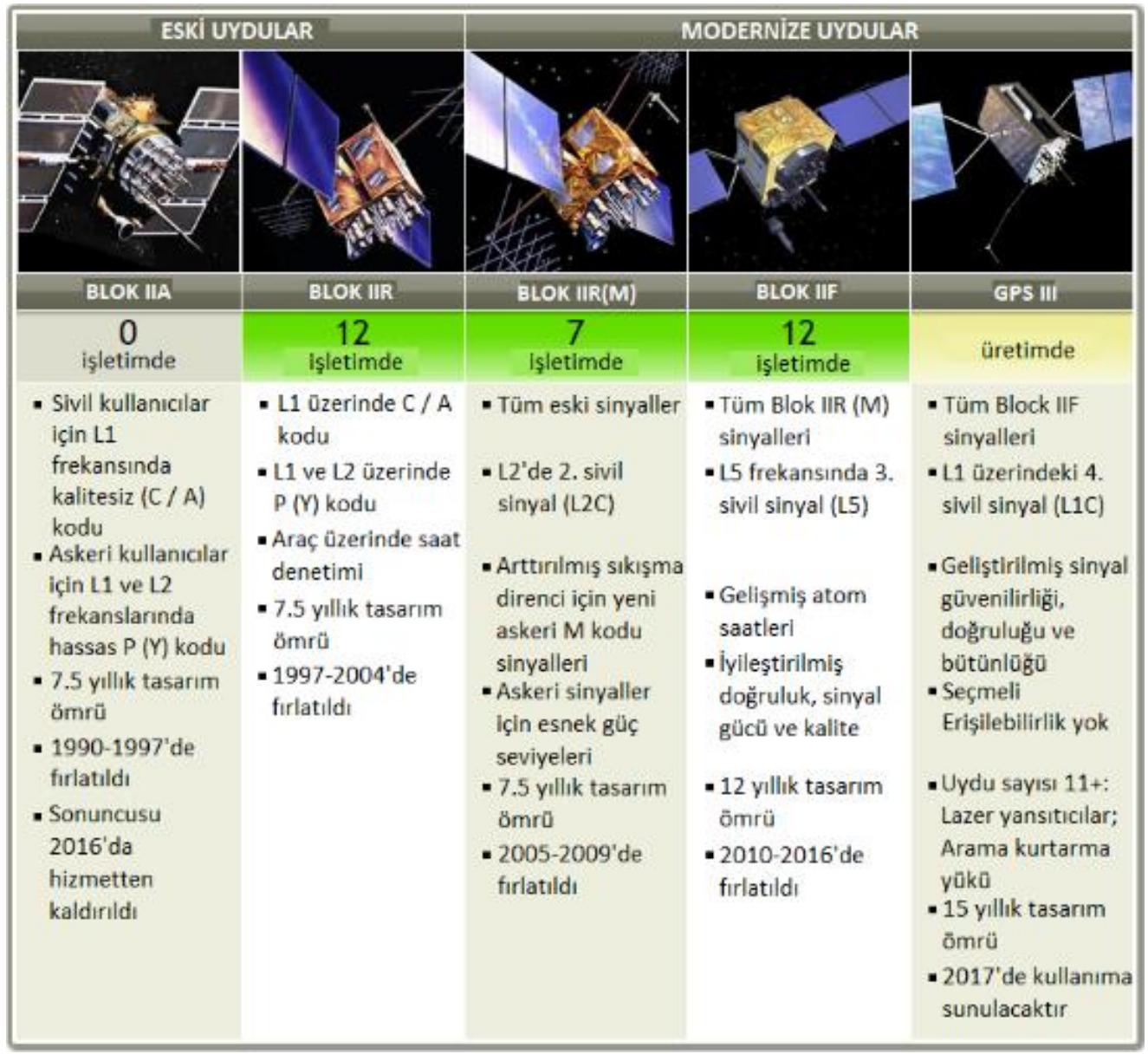


GPS'in modernizasyonu programının asıl odak noktası, uydu sistemi için yeni navigasyon sinyallerinin eklenmesidir. Sistemde, sivil amaçlı tasarlanmış üç yeni sinyal bulunmaktadır: L2C, L5 ve L1C, L1'de L1 $\mathrm{C} / \mathrm{A}$ veya $\mathrm{C} / \mathrm{A}$ olarak adlandırılan eski sivil sinyal ile birlikte gelecekte dört sivil GPS sinyali yayını yapılacaktır. Kullanıcıların, yeni sinyallerden yararlanabilmek için donanımlarını da iyileştirmeleri gerekecektir.

L2C, ticari ihtiyaçları karşılamak için özel olarak tasarlanmış ikinci sivil GPS sinyalidir. L2C adı, sinyalin kullandığı radyo frekansını (1227 MHz veya L2) ve bunun sivil amaçlı olduğunu belirtir. Mevcut çift frekanslı işlemlere sahip profesyonel kullanıcılar için L2C, daha hızlı sinyal alımı, arttırılmış güvenilirlik ve daha geniş çalışma aralığı sunmaktadir. L2C, eski L1 C/A sinyalinden daha yüksek güçle yayın yapma imkânı sunmaktadır. Böylece ağaçların altında ve hatta iç mekânlarda daha kolay çalışma imkânı sunmaktadır. L2C'nin kullanımı sayesinde 2030 y1lına kadar ekonomik verimlilik avantajlarından $\quad 5,8 \quad$ milyar dolar kazanabileceği tahmin edilmektedir (URL 4). L2C özellikli ilk GPS IIR (M) uydusu 2005 yılında hizmete sunulmuştur.

2014 Nisan ayında ABD Hava Kuvvetleri L2C ve L5 sinyallerinde sivil navigasyon (CNAV) mesajı yayınlamaya karar vermiştir. Bu amaçla GPS kontrol bölümünde bazı güncellemeler yapılmıştır (URL 4).

L5, can güvenliği ve diğer yüksek performanslı uygulamalar için zorlu gereksinimleri karşılamak üzere tasarlanmış üçüncü bir sivil GPS sinyalidir. L5 sinyalinin frekans1 1176 $\mathrm{MHz}$ dir. L5, sadece havacilık güvenliği hizmetleri için ayrılan bir radyo bandında yayınlanmaktadır.

Gelecekte L1 C/A ile L5'in birlikte kullanılması planlanmıştır. L5'in kullanımı ile sistemin doğruluğunun yanında, havayolları, demiryolları, denizyolları ve otoyollardaki kapasite kullanımını ve yakıt verimliliğini artırması hedeflenmiştir. L5 sinyali L1 C/A ve L2C sinyallerinin birlikte kullanımı (Trilaning) ile metre altı (sub-meter) doğruluk ve çok uzun bazlarla çalışma imkânı sunulmuştur (URL 5).

2009 yılında ABD Hava Kuvvetleri, GPS IIR20 (M) uydu üzerinden test amaçlı L5 sinyali başarıyla yayınlamıştır. Mayıs 2010'da L5 vericisi bulunan ilk GPS IIF uydusu sisteme eklemiştir. Nisan 2014'te ABD Hava Kuvvetleri L2C ve L5 sinyallerinde sivil navigasyon (CNAV) mesaj yayınlamaya başlamıştır.

L1C, GPS ve uluslararas1 uydu navigasyon sistemlerinin birlikte çalışabilirliğini sağlamak üzere tasarlanan dördüncü sivil GPS sinyalidir. L1C ad1, sinyalin (1575 MHz veya L1) kullandığ 1 radyo frekansina ve bunun sivil amaçlı kullanılması anlamına gelmektedir. L1'de iki askeri sinyalin yanı sira eski C/A sinyali de vardır. L1C ve L1 C / A ile karıştırılmamalıdır.

L1C, ABD ulusal güvenlik çıkarlarını koruyarak uluslararası işbirliğini mümkün kılan Çok Yönlü İkili Ofset Taşıyıcı (Multiplexed Binary Offset Carrier-MBOC) modülasyon tasarımına sahiptir (URL 6).

ABD ve Avrupa ilk olarak L1C'yi GPS ve Galileo için ortak bir sivil sinyal olarak geliştirmiştir. L1C sinyali, GPS III uyduları ile yayınlanması planlanmıştır. L1C geriye dönük uyumluluk için korunacak olan orijinal L1 C/A sinyaliyle aynı frekansta yayı yapmaya devam edecektir.

Seçmeli Erişilebilirlik (SA), ulusal güvenlik nedenleri uygulanan kamusal GPS sinyallerinin kasitlı olarak bozulmasidir. Seçmeli Erişilebilirlik (SA), kullanımını, Mayıs 2000 de GPS'i tüm dünyadaki sivil ve ticari kullanıcılara daha duyarlı hale getirmek için durdurmuştur. SA'nın devre dişı bırakılmasından öncesi ve sonras1 GPS'in doğruluğu Şekil 2'de verilmiştir. 


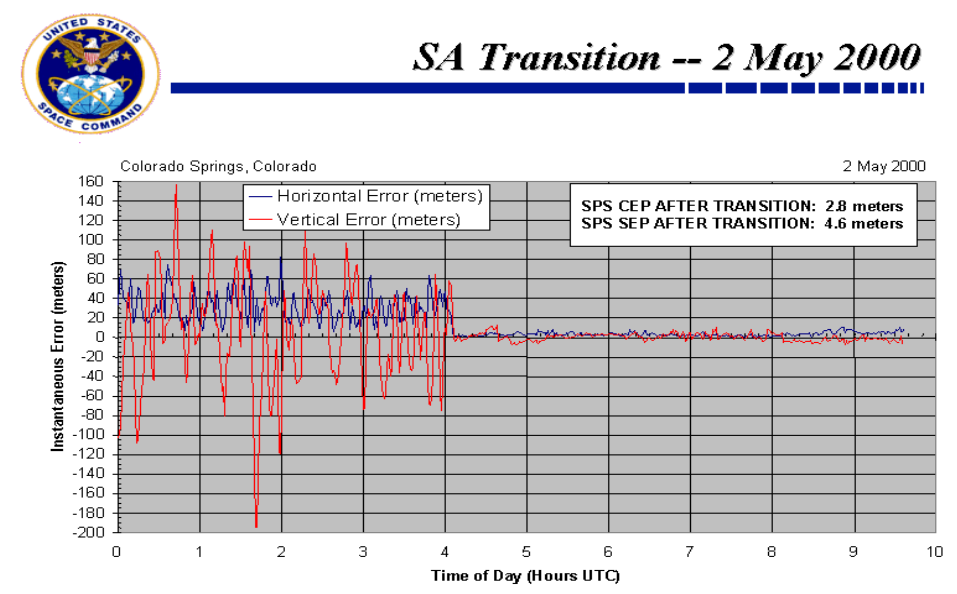

Şekil 2. SA öncesi ve sonrası GPS'in doğruluğu (Conley R.2000), (URL 7)

\subsection{GLONASS}

GLONASS, Rusya Federasyonu tarafindan geliştirilmiş uydu konum belirleme sistemidir.

GLONASS'in ilk testleri Kosmos-1413, Kosmos-1414 ve Kosmos-1415 uydularının uzaya firlatılması ile 12 Ekim 1982'de başlanmış olmasına rağmen sistem 1995 y1linda 24 uydu ile optimal seviyede çalışmaya başlamıştır (Şekil 3), (URL 8).

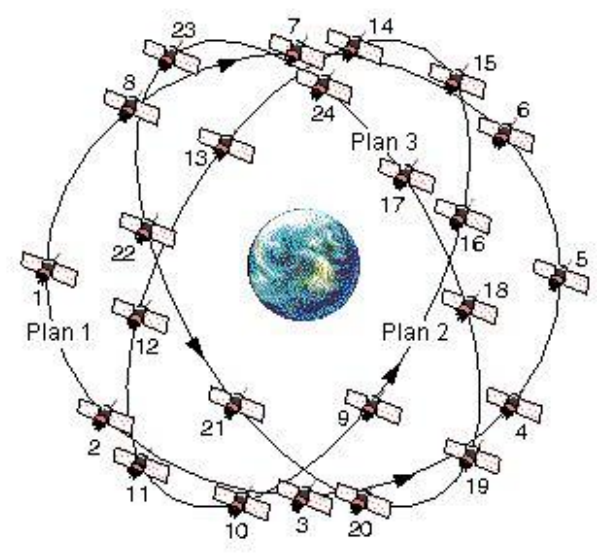

Şekil 3. GLONASS Uydu Bazlı Navigasyon Sistemi

\subsubsection{GLONASS Sisteminin Gelişimi ve Geleceği:}

Rusya hükümeti, 20 Ağustos 2001 tarihinde GLONASS sistemini geliştirmesi programını kabul etmiştir. Bu program ile GLONASS performansinın GPS'den daha kötü olması, atom saatlerinin performans1, sistemin uydu sayısı ve zemin bölümünün izlenmesi, denetimi ve Rus topraklarıyla sinırlı olduğu gerçeği de dahil olmak üzere birçok faktörü geliştirmeyi amaçlanmıştır. GLONASS, 2020 yılına kadar sistemdeki tüm uyduların hem yeni Code Division Multiple Access (CDMA) hem de eski FDMA sinyallerini iletmesi planlamaktadır.

GLONASS uyduları, diğer tüm GNSS sistemlerinin kullandığı CDMA'nın aksine Frequency Division Multiple Access (FDMA) tekniğine dayanan navigasyon radyo sinyallerini iki frekans alt-bandında (L1 $\sim 1602 \mathrm{MHz}$ ve L2 $1246 \mathrm{MHz}$ ) yayın yapmaktadır. Daha iyi doğruluk, multipath etkisi ve özellikle GPS, GALILEO ve diğer GNSS Sistemleri ile daha uyumlu çalışabilirlik hedefleyen yeni GLONASS-K uyduları, sistemin geleneksel FDMA sinyallerine ek olarak CDMA sinyalleri yayınlamaktadır (URL 9).

GLONASS Uzay Birimi modernizasyonu, ikinci nesil GLONASS-M uydularyyla başlamıştır. Yeni filtreler, out-of-band emisyonların azaltılmasina ve 24 saat boyunca dahili saat kararlılığının $5 \times 10^{-13}$ ten $1 \times 10^{-13} \mathrm{e}$ yükseltilmesine imkân sağlamıştır. Eski 
uyduların modernize edilmesi amaciyla

GLONASS-M uydularının ilk uydusu Nisan 2013'te firlatılmıştır (Revnivykh S.2010), (URL 11).

Üçüncü kuşak uydu olan GLONASS-K1'in ilk uydusu 26 Şubat 2011'de kullanılmaya başlanmıştır. İkinci uydu ise 30 Kasım 2014'te uzaya firlatılmıştır. Ardından 10 yıllık bir tasarım ömrüne sahip ve L3 bandında 1205 MHz frekanslı CDMA sivil sinyali taşıyan 9 GLONASS-K1 uydusu daha firlatılmıştır. İkinci GLONASS-K1 uydusu, 15 Şubat 2016'da, 6 numaralı kanalda GLONASS sisteminin 2. düzlemindeki 9. yörüngesinden düzenli yayınlara başlamıştır (URL 12).

GLONASS-K2 uydularının ilk olarak 2014 yılına kadar firlatılması planlanmıştı ancak plan değiştirilerek 2018'e ertelenmiştir. GLONASS-K2 uydular1 10 yıllık tasarım ömrüne ve $\sim 5-1 \times 10^{-14}$ saatlik bir kararlılığa sahip olacaktır. L3 üzerindeki CDMA sinyallerine ek olarak, L1 ve L2 üzerinde CDMA sinyalleri de iletilecektir. GLONASS- değiştirilmesi planlanan

$\mathrm{K}$ uyduları hem eski FDMA hem de CDMA sinyallerini iletecektir.

Uragan-K2 (GLONASS-K2) uydular1 Uragan-K1 (GLONASS-K1) uydu serisinin geliştirilmiş sürümüdür. Uragan-K2 uydularının firlatma işleminin 2017 sonunda tamamlanmas1 ve 2020 'den itibaren K1 sürümünün yerini alması planlanmaktadır (Tablo 2).

Uragan uydularının bir başka ve son versiyonu olan, GLONASS-KM olarak bilinen uydular navigasyon ağının kabiliyetini daha da genişletecektir. Ancak bu uydu sürümün 2020'li y1llardan önce kullanılamayacağ1 belirtilmektedir (Revnivykh, 2010).

GLONASS uydu yörünge doğruluğunun artırılası amaciyla, altı tanesi Rusya toprakları dışında olmak üzere, Antarktika'ya kurulan ilk referans istasyonunun yanı sıra on beş yeni referans istasyonu daha kurulmas1 planlanmıştır (Şekil 4).

Tablo 2. GLONASS uyduları ve özellikleri (URL 10)

\begin{tabular}{|c|c|c|c|}
\hline GLONASS & GLONASS-M & GLONASS-K & GLONASS-K2 \\
\hline $1982-2005$ & 2003-2016 & 2011-2018 & $2017+$ \\
\hline $\begin{array}{l}\text { - } 3 \text { yıllık tasarım } \\
\text { ömrü } \\
\text { - Saat hassasiyeti } \\
5^{*} 10^{-13} \\
\text { - Sinyaller: L1SF, } \\
\text { L2SF, L1OF, } \\
\text { (FDMA) } \\
\text { - Toplam } 81 \text { uydu } \\
\text { fırlatıldı } \\
\text { - Aktif işletme } \\
\text { ömrü } 4.5 \text { yıl }\end{array}$ & $\begin{array}{l}\text { - } 7 \text { yıllık tasarım } \\
\text { ömrü } \\
\text { - } \quad \text { Saat hassasiyeti } \\
1^{*} 10^{-13} \\
\text { - } \quad \text { Sinyaller: } \\
\text { Glonass +L2OF } \\
\text { (FDMA) } \\
\text { - Toplam } 39 \text { uydu } \\
\text { fırlatıldı }\end{array}$ & $\begin{array}{l}\text { - } 10 \text { yıllık tasarım ömrü } \\
\text { - Platform Tasarımı: } \\
\text { Basınçsız } \\
\text { - Beklenen saat } \\
\text { hassasiyeti }{ }^{\sim} 10 . . .5^{*} \\
10^{-14} \\
\text { - Sinyaller: Glonass-M } \\
+ \text { L3OC (CDMA) } \\
\text { - Search And Rescue } \\
\text { (SAR)-Arama } \\
\text { Kurtarma }\end{array}$ & $\begin{array}{l}\text { - } 10 \text { yıllık tasarım ömrü } \\
\text { - } \text { Platform Tasarımı: } \\
\text { Basınçıı } \\
\text { - } \quad \text { Beklenen saat } \\
\text { hassasiyeti } ~ 55_{. . .1 * 10^{-14}} \\
\text { - Sinyaller: Glonass-M + } \\
\text { L1OC, L3OC, L1SC, } \\
\text { L2SC (CDMA) } \\
\text { - Search And Rescue } \\
\text { (SAR)-Arama } \\
\text { Kurtarma }\end{array}$ \\
\hline
\end{tabular}




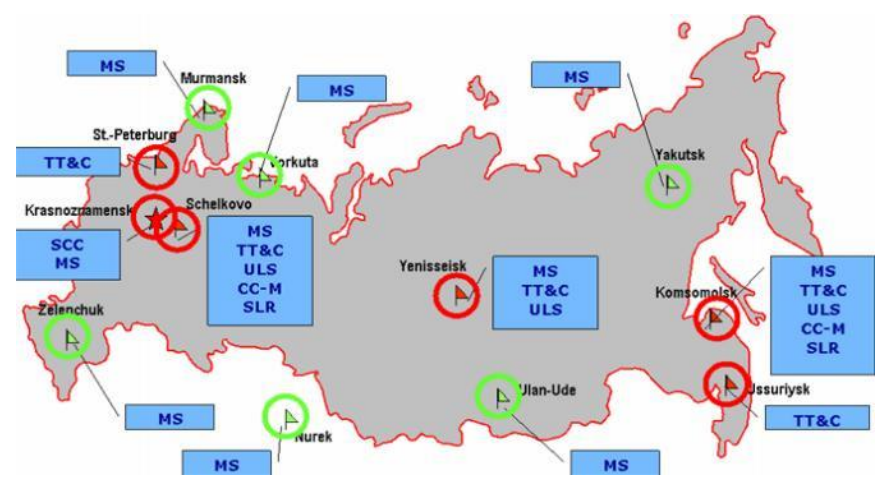

SCC: System Control Centre

TT\&C: Telemetry, Trackingand

Command

SLR: Laser Ranging Stations

MMS: Monitoringand Measuring

Stations

ULS: Uplink Station

MS: Monitoring Station

CC: Central Clock

Şekil 4. GLONASS Yer kontrol Bölümü (Revnivykh, 2008)

Bu sayede, 2008 yılındaki yörünge doğruluğu, 120 milimetre seviyesinde iken 2009 sonu itibariyle 85 milimetre seviyesine düştüğü belirtilmiştir (Langley 2010), (URL 13).

GLONASS koordinat sistemi, diğer GNSS sistemleri ile birlikte çalışabilirliği artırmak amaciyla International Terrestrial Reference System (ITRF) bağlanmıştır (URL 14).

\subsection{GALİLEO SİSTEMI:}

Galileo Sistemi, Avrupa'nın kontrolündeki, global ve bağımsız olarak çalışan uydu bazlı bir navigasyon sistemidir. Galileo sistemi, uyumlu alıcılarla donatılmış kullanıcılara hizmet sunacaktır.

Galileo Sisteminin alt yapısı Şekil 5'de verilmiştir. Sistemin alt yapısı, Orta Dünya Yörüngesindeki (MEO) 30 uydu, saat senkronizasyonu ve yörünge ölçümleri için kapsama alanı sağlayan küresel bir Galileo Sensor Stations (GSS) ağı, iki Kontrol Merkezi ve iki firlatma öncesi operasyon (LEOP) Merkezi, bir Görev yerleşim istasyonları ağı ve İzleme ve Kontrol (TT \& C) istasyonlarından oluşmaktadır (Şekil 5).

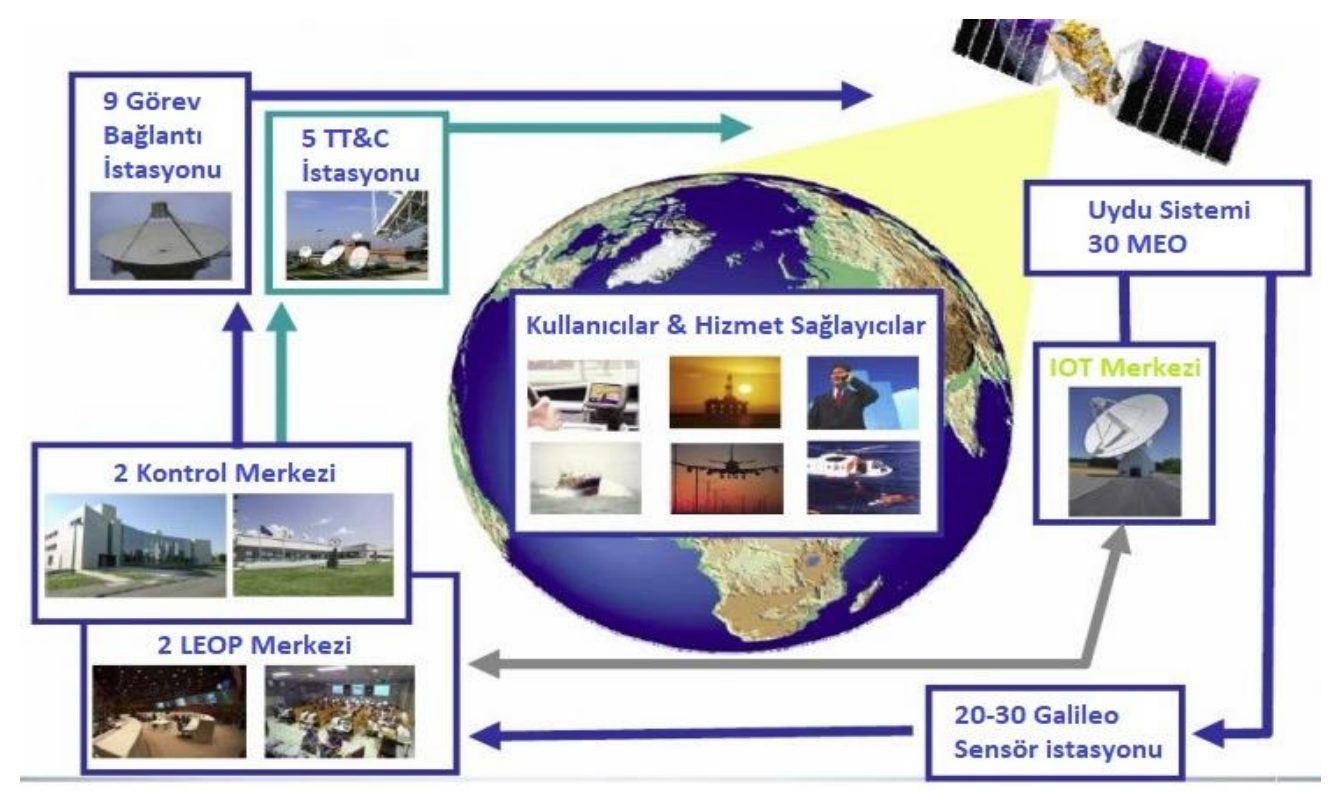

Şekil 5. GALILLEO Sisteminin alt yapıs1 


\subsubsection{Galileo sisteminin gelişimi ve geleceği}

Galileo programı, Avrupa'nın kontrolünde ve sivil kullanımı altında olan son derece doğru ve güvenilir küresel konumlandırma hizmeti sağlayan, en son teknoloji ürünü bir küresel uydu navigasyon sistemidir. Galileo programı altında kurulan sistem, özerk navigasyon ve konumlama hizmetleri sunarken, aynı zamanda GPS ve GLONASS gibi diğer GNSS sistemleri ile birlikte çalışabilecektir.

Galileo Projesi her ne kadar bir Avrupa Birliği ortak projesi gibi görünse de bu büyük ve tarihi projeye Avrupalı olmayan ülkeler de dahil olmuştur. 2003 Eylül ayında Çin, 2004 Haziran'da İsrail, 2005 Haziran' da Ukrayna, 2005 Eylül'de Hindistan ve Fas, 2006 y1lında Güney Kore ve $A B$ üyesi olmayan Avrupa ülkesi Norveç programa dahil olmuştur.

Avrupa Birliği üyesi 27 ülke ise uzun tartı̧̧malar sonucunda 2007 yılında topluca programa dahil olmuşlardır. İlk başlarda katılmayı reddeden İspanya'nın da katılmayı kabul etmesiyle beraber, projenin finansman problemleri sona ermiş ve resmen bir Avrupa Birliği projesi haline gelmiştir. Arjantin, Avustralya, Brezilya, Japonya, Kanada, Malezya, Meksika, Pakistan, Rusya ve Şili de geliştirme programının üyesi olabileceklerini kesin olmamakla birlikte zaman zaman dile getirmişlerdir.

Galileo sisteminin gelişimi halen Avrupa Uzay Ajansı (ESA) tarafindan yürütülen bir program olan European GNSS Evolution Programme (EGEP) kapsamında teknik bir çalışma içinde yürütülmektedir. Birincil amac1, Space-Based Augmentation Systems(SBAS) ve Global Navigation Satellite Systems (GNSS) ile ilgili teknolojik araştırma ve geliştirmeleri yapmaktır. Sistemin, 2019-2020 yıllarına kadar çalışır duruma gelmesi planlanmaktadır (URL 15).

\subsection{BeiDou Sistemi:}

BeiDou-2 olarak da bilinen BeiDou Navigasyon Uydu Sistemi (BDS), kullanıcılara kesintisiz dünya çapında konumlama, navigasyon ve zamanlama hizmetleri sağlayan Çin'in ikinci nesil uydu navigasyon sistemidir.

BeiDou sisteminin uzay bölümü, 2020 yılında tamamlandığında 35 uydudan oluşacaktır. Bunlar arasında 5 adet geostationary yörünge (GEO) uyduları ve 30 adet non-GSO uydusu dur. BeiDou sistemi, dünya çapında bir kapsama alanına sahip olacak şekilde tasarlanmıştır (URL 19).

BeiDou sisteminin yer kontrol Bölümü, bir Ana Kontrol İstasyonu, bir Yükleme İstasyonları ve birkaç İzleme İstasyonundan oluşmaktadır (URL 16).

BeiDou Sistemi, Aralık 2011'de konumlama hizmeti vermeye başlamışıı ve 2012 Münih Uydu Navigasyon Zirvesinde bildirilen ilk performanslar şunlardır:

- Hizmet Kapsamı: Bölgesel

- Konumlandırma Doğruluğu: 25 metre yatay ve 30 metre düşeyde

- Zamanlama Hassasiyeti: $50 \mathrm{~ns}$

- Hzz hassasiyeti: $0,4 \mathrm{~m} / \mathrm{s}$

$\mathrm{Bu}$ performansların, yörüngedeki uyduların sayısı arttıkça ve kullanıcı birimi geliştikçe iyileşmesi beklenmektedir (URL 17) (Şekil $6)$.

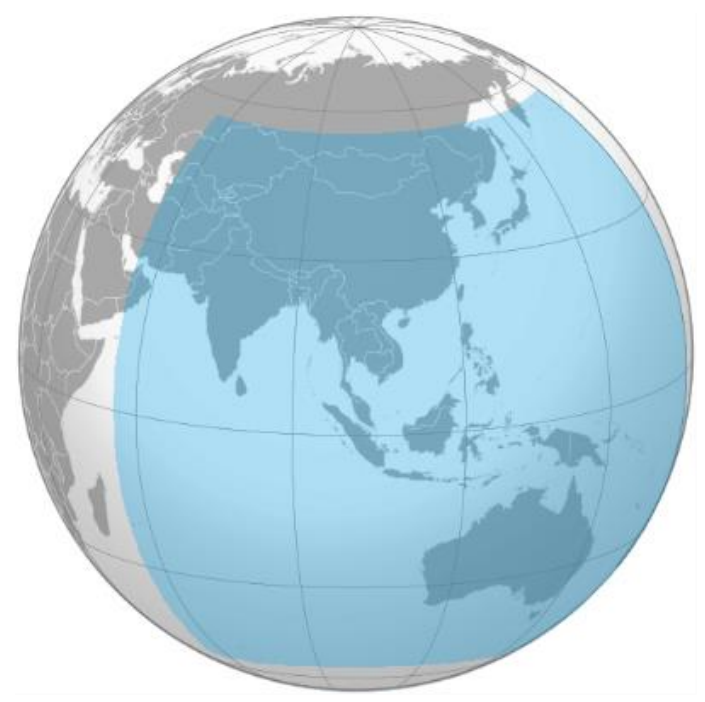

Şekil 6. Beidou-2 kapsama alanı 


\subsubsection{BeiDou sisteminin geleceği ve gelişimi:}

BeiDou sisteminin gelişimi üç aşamada ele alınabilir.

Birinci Aşama (2003+); Aktif bir navigasyon servisi sağlayan deneysel bir bölgesel navigasyon sistemi BeiDou-1'den oluşur.

İkinci Aşama (2012+); BeiDou-2 olarak isimlendirilir ve Çin üzerinde hizmet sunmaktadır. $\mathrm{Bu}$ aşamada, pasif konumlandirma ve zamanlama kabiliyeti olan bir sistemin bölgesel bir alana yaymayı amaçlanmıştır.

Üçüncü Aşama (2020+); BeiDou sistemi, 2020 yılına kadar 27 MEO, 5 GEO ve 3 IGSO uydusuyla tam kapasiteye ulaşacaktır. BeiDou sistemi, GPS, GLONASS ve Galileo gibi şekilde küresel navigasyon hizmeti sunacaktır (URL 18).

\subsection{IRNSS Uydu Sistemi}

IRNSS uydu sistemi, Hindistan Uzay Araştırmaları Kurumu (ISRO) tarafindan geliştirilen bölgesel bir uydu navigasyon sistemidir. Sistem ikisi yedek olmak üzere dokuz uydudan oluşmaktadır. Nisan 2016'da, uydu sisteminin son uydusunun firlatılmasiyla birlikte, IRNSS, Hindistan Başbakanı Narendra Modi tarafindan Navigation Indian Constellation (NAVIC) olarak yeniden adlandırılmıştır.

IRNSS, Hindistan çevresindeki 1500 kilometrelik bir alanda çalışmayı hedefleyen bağımsız ve özerk bir bölgesel uydu tabanlı navigasyon sistemidir. NAVIC sistemi tam olarak hizmete sokulduğuna GEO yörüngede 3 uydu ve GSO yörüngede 4 uydu ile yeryüzü üzerinden yaklaşık $36.000 \mathrm{~km}$ yüksekte hizmet verecektir (Şekil 7), (URL 20).

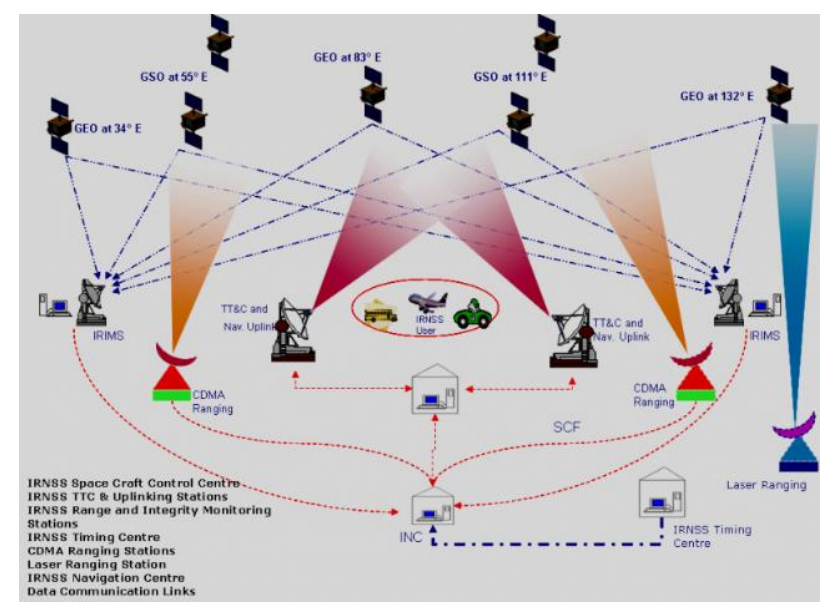

Şekil 7. IRNSS uyduları ve çalışma prensibi

IRNSS projesinin yapımına Mayıs 2006 tarihinde başlanmıştır. Uydu sistemindeki üç GSO uydusunun ilk uydusu olan IRNSS-1A, 1 Temmuz 2013'te başarılı bir şekilde fırlatılıştır. 2016 yılında projenin son uydusu yörüngeye gönderilmiştir. Yedek uyduların ise 2017 y1lında uzaya gönderilmesi planlanmaktadır (URL 21).

IRNSS sisteminden; Hint Okyanusu Bölgesi'nde (Hindistan'da 1500 km'lik) $20 \mathrm{~m}$, Hindistan ve çevre ülkelerde ise 10 m'nin altında konum doğruluğu beklenilmektedir (URL 22).

\subsection{QZSS Sistemi:}

Quasi-Zenith Satellite System (QZSS), Japonya'yı kapsayacak şekilde Japonya Uzay Araştırma Ajansı (JAXA) tarafından geliştirilmiş, uydu tabanlı navigasyon sistemidir. İlk uydusu 2010 y1lında fırlatılmıştır. QZSS sistemi, 32000-40000 km yükseklikteki 4 uydudan oluşmaktadır.

QZSS hizmet bölgesi Doğu Asya ve Okyanusya bölgesini kapsamaktadır QZSS sistemini diğer GNSS sistemine ait uydularından gelen verilerle birlikte çalışabilmektedir. Sistemin uzay bölümü, 
Highly Elliptical yörüngede (HEO) üç uydu ve geo-stationary yörüngede bir uydu olmak üzere dört uydudan oluşmaktadır. HEO'daki uyduların yeryüzünden uzaklıkları yaklaşık $32000 \mathrm{~km}$ ve tepe noktası yüksekliği yaklaşık $40000 \mathrm{~km}$ 'dir. Uyduların hepsi aynı yeryüzü rotasından geçmektedir. QZSS sistemi, üç uydusundan en az biri Japonya üzerinde olacak şekilde tasarlanmıştır (Şekil 8). QZSS uyduların tasarım ömrü 10 yıldır (URL 23).

QZSS Sistemi, GPS uyduları ile entegre bir şekilde kullanılacak olup, ilerleyen yıllarda sistemin uydu sayısının 7'e yükseltilmesi planlanmaktadır (Şekil 9), (URL 24).

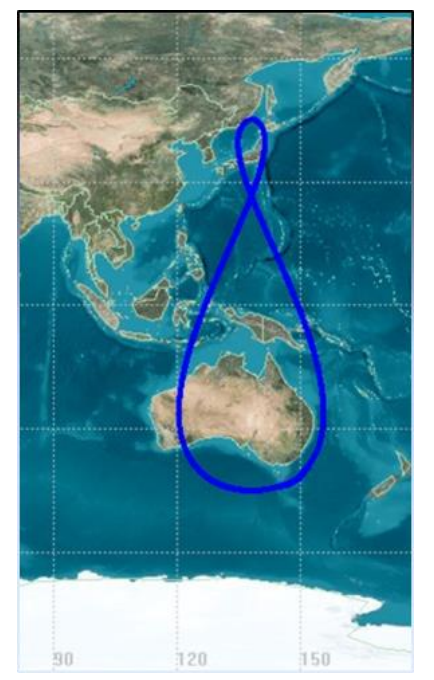

Şekil 8. QZSS uydu yörünge rotası

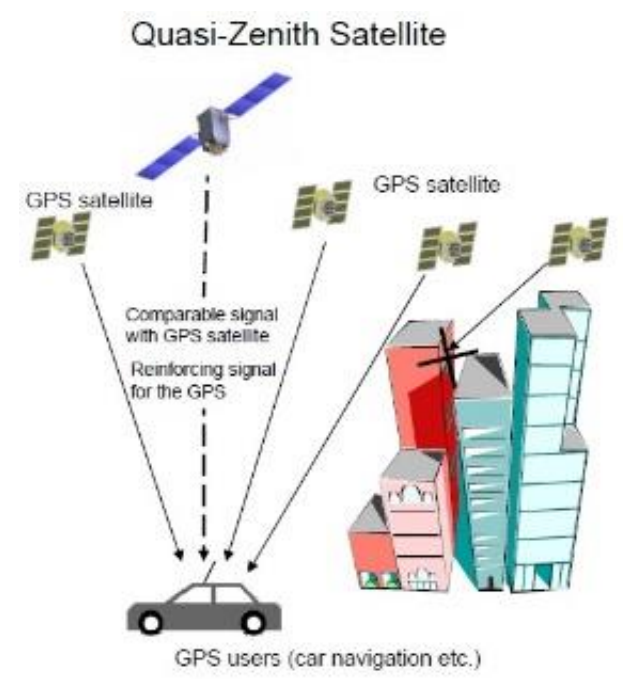

Şekil 9. QZSS ve GPS entegrasyonu

\section{SONUÇLAR}

$\mathrm{Bu}$ çalışmada, halen kullanılmakta olan ve yapım aşamasında olan Küresel ve Bölgesel Uydu Konum Belirleme Sistemlerindeki güncel gelişmeler yanında ileriki yıllarda ne gibi güncellemelerin yapılacağ 1 ve bu gelişmeler çerçevesinde ne tür kullanım alanlarına sahip olacağ 1 ele alınmıştır. Ayrıca, yapım aşamasında olan sistemlerin hangi aşamada oldukları, sistemlerin hangi tarihte tam kapasiteye çalışır duruma geleceği ve ne şekilde çalışacağ 1 konusunda bilgiler verilmiştir.

GPS, A.B.D. Savunma Bakanlığı tarafindan geliştirilen ve şu anda tam kapasite ile çalışan Küresel uydu navigasyon sistemidir. GPS'in BLOCK III uyduları ile güncellenmesi, sisteme sivil amaçlı tasarlanmış üç yeni sinyalin eklenmesi (L2C, L5 ve L1C) planlanmaktadır (URL 25).

GLONASS, Rusya Federasyonu tarafindan geliştirilen ve halen tam kapasite ile çalışan ve GPS'den sonra küresel kapsama alanına sahip ikinci uydu konum belirleme sistemdir. 2001 yilında devreye sokulan GLONASS'ın geliştirmesi programı ile GLONASS performansının iyileştirilmesi amaçlanmıştır. GLONASS, 2020 yılına kadar sistemdeki tüm uyduların hem yeni CDMA hem de eski FDMA sinyallerini iletmesi ve sistemdeki uyduların K1, K2 ve KM uyduları ile güncellenmesi planlanmaktadır (URL 26).

GALILLEO, Avrupa Uzay Ajansı tarafindan çalışmaları yürütülen, şuan kurulum aşamasında olan sistemin, deneysel amaçlı olarak firlatılmış olan GOVE-A ve GOVE-B uydular1 ile birlikte uzayda 20 adet uydusu bulunmaktadır. 30 uydudan oluşacak olan sistemin 2020 y1lını sonuna kadar kurulumunun tamamlanmasi planlanmaktadır (URL 27).

BEIDOU, Çin Halk Cumhuriyeti tarafından çalışmaları 2000 yılından bu yana bölgesel olarak faaliyet gösteren navigasyon sistemi, 2020 yılından itibaren küresel kapsama alanına erişmesi planlanmaktadır (URL 28)

IRNSS (NAVIC), Hindistan Bölgesel Seyir Uydu Sistemi (IRNSS) ikisi yedek olmak üzere dokuz uydudan oluşmaktadır. Nisan 2016'da, uydu sisteminin son uydusunun firlatılmasinın ardından sistemin ad1 Navigation Indian Constellation (NAVIC) 
olarak yeniden adlandırılmıştır. Yedek uyduların ise 2017 yılında uzaya gönderilmesi planlanmaktadır (URL 21).

QZSS, Japonya'y1 kapsayacak şekilde Japonya Uzay Araştırma Ajansı (JAXA) tarafından geliştirilmiş, uydu tabanlı navigasyon sistemidir. GPS sistemine entegre bir şekilde çalışması düşünülen sistemin ilk uydusu 2010 yılında firlatılmıştır. Sistemin 2018 yılından itibaren 4 uydu ile 2023 yılından itibaren 7 uydu ile çalışması planlanmaktadır (URL 29).

\section{KAYNAKÇA}

Conley R. (2000). GPS Support Center, Air Force Space Command, Springs- Colorado, GPS.GOV internet sitesi bildiri (URL 7:http://www.gps.gov/systems/gps/modern ization/sa/data/2 10.08.2017

Langley R. B. (2010) Innovation: GPS, GLONASS, and More_University of New Brunswick (UNB) in Fredericton, Canada, "Innovation: GPS, GLONASS, and More" makalesi

(URL

13:http://gpsworld.com/innovation-gpsglonass-and-more/) 10.08.2017

Revnivykh S. (2008) GLONASS Status and Progress, CGSIC-Meeting-Savannah, GA, US, "GLONASS Status and Progress" sunumu 1-7,

(https://www.navcen.uscg.gov/pdf/cgsicM eetings/48/Reports/International\%20Subc ommittee/[24]\%20GLONASS\%20CGSIC \%2016.09.2008.pdf.) 10.08.2017

Revnivykh S. (2010) GLONASS Status and Progress, Deputy Director General Central Research Institute of Machine Building Head of PNT Center, CGSIC-PortlandOregon, "GLONASS Status and Progress" sunumu $13-16$, (https://www.navcen.uscg.gov/pdf/cgsicM eetings/50/[3]CGSIC_GLONASS_Revniv ykh_20_09_2010.pdf.) 10.08.2017

GPS World (2014) New GPS IIF Satellite Launched, GPS World bildiri, (URL 2:http://gpsworld.com/new-gps-iifsatellite-launched/) 10.08.2017

Ylldiz F., Kahveci M. (2010) GPS/GNSS Uydularla Konum Belirleme SistemleriTeori ve Uygulama Kitabi, Nobel Yayınları, 3, Ankara.

URL1:http://www.gps.gov/systems/gps/space/ (11.08.2017)

URL3:http://www.gps.gov/systems/gps/space/\#ge nerations $(11.08 .2017)$

URL4:http://www.gps.gov/systems/gps/moderniza tion/civilsignals/ (13.08.2017)
URL5:http://www.gps.gov/systems/gps/moderniza tion/civilsignals/\#L5 (13.08.2017)

URL6:http://www.gps.gov/systems/gps/moderniza tion/civilsignals/\#L1C (13.08.2017)

URL8:http://www.navipedia.net/index.php/GLON ASS_General_Introduction (18.08.2017)

URL9:http://www.navipedia.net/index.php/GLON ASS_Future and Evolutions\# Signal Modernization (18.08.2017)

URL10:https://www.glonass-iac.ru/en/guide/ (18.08.2017)

URL11:http://www.navipedia.net/index.php/GLO NASS Future and Evolutions (20.08.2017)

URL12:http://www.navipedia.net/index.php/GLO NASS_Future_and_Evolutions\#Space_Se gment (20.08.2017)

URL14:http://www.navipedia.net/index.php/GLO NASS_Future_and_Evolutions\# Ground_Segment (20.08.2017)

URL15:http://www.navipedia.net/index.php/Galile o_Future_and_Evolutions\#Galileo _phases (20.08.2017)

URL16: $\underline{\text { http://www.navipedia.net/index.php/BeiD }}$ ou_Architecture (21.08.2017)

URL17:http://www.navipedia.net/index.php/BeiD ou_Performances (21.08.2017)

URL18:http://www.navipedia.net/index.php/BeiD ou_Future and Evolutions (23.08.2017)

URL19:https://www.glonassiac.ru/en/guide/beidou.php (23.08.2017)

URL20:http://www.navipedia.net/index.php/NAVI C\#IRNSS_Architecture (23.08.2017)

URL21:http://www.isro.gov.in/missions-0 (25.08.2017)

URL22:http://www.navipedia.net/index.php/NAVI C\#IRNSS Services and Performances (25.08.2017)

URL23:http://www.navipedia.net/index.php/QZSS (25.08.2017)

URL24:http://qzss.go.jp/en/overview/services/sv0 2_why.html (25.08.2017)

URL25:https://www.glonass-iac.ru/en/GPS/ (28.08.2017)

URL26: https://www.glonass-iac.ru/en/GLONASS/ (28.08.2017)

URL27:https://www.n2yo.com/satellites/?c=22 (28.08.2017)

URL28:https://www.glonass-iac.ru/en/BEIDOU/ (28.08.2017)

URL29:http://qzss.go.jp/en/overview/services/sv0 1_what.html $(28.08 .2017)$ 